\title{
ANÁLISE ESTATÍSTICA DO GERENCIAMENTO E REAPROVEITAMENTO DE RESÍDUOS DA CONSTRUÇÃO CIVIL
}

\section{STATISTICALANALYSISMANAGEMENT AND REPRODUCTION OF WASTE FROM CIVIL CONSTRUCTION}

Nilo Antonio de Souza Sampaio * nilo.samp@terra.com.br

Caio Silva Werneck ** caioswerneck@outlook.com

Ricardo Pereira Abraão ** ricardopereiraabraao@gmail.com

Letícia Duarte Martins ** leticiadm@hotmail..com

João Vitor Rangel do Nascimento ** Joaovitor.rangel@hotmail.com

Adrízia Cordeiro Hygino ** adriziahygino@hotmail..com

Ywan Yago Silva Nunes de Souza ** leticiadm@hotmail..com

* Faculdade Sul Fluminense, Volta Redonda - Brasil

** Universidade do Estado do Rio de Janeiro, Rio de Janeiro - Brasil

\section{Resumo Resumen Abstract}

A expansão urbana e o celebre adensamento das cidades de médio e grande porte, tem provocado inúmeras dificuldades para destinação do grande volume de resíduos gerados pelas atividades privadas de construção, reformas e demolição de edificações, além daquelas obras públicas de construção e adequação estruturais, levando os administradores municipais a buscarem soluções mais eficazes para gestão do problema. Os resíduos de concreto apresentam grande potencial para serem reciclados comparados com outros resíduos, entretanto, o número de estudos realizados no Brasil é muito pequeno dificultando a utilização deste material em dosagens estruturais. Em virtude disso, desenvolve-se um estudo teórico-experimental visando minimizar o impacto causado ao meio ambiente e caracterizar as propriedades do agregado e do concreto reciclado; no estudo teórico exploram-se aspectos realizados à geração, deposição, processos para recuperação, britagem, casos práticos, pesquisas envolvendo reciclados de concreto e as recomendações normativas existentes. No desenvolvimento experimental, analisou-se a influência do período decorrido entre a moldagem e a reciclagem nas propriedades dos agregados e concretos. Os resultados indicam que resíduos reciclados após a sua geração, contribuem positivamente para as propriedades mecânicas do concreto, devido à existência de grande quantidade de partículas não-hidratadas de cimento, tais concretos obtiveram resultados superiores para resistência à compressão e tração quando comparados aos concretos com agregados naturais. Assim, o objetivo desta pesquisa é estudar a viabilidade da reutilização do agregado reciclado de concreto e misto, através da análise de resultados de ensaios laboratoriais, com base em uma pesquisa de substituição gradativa do agregado miúdo, visando também que em razão das suas propriedades físicas e mecânicas de concreto, o RCC (Resíduo de Construção Civil) é adequado para substituir os agregados naturais de concreto. Resultado que nos faz considerar esse material como uma alternativa viável em concretos estruturais, bases de 
pavimentações e artefatos de concreto podem ser adotados pelo município de Resende e outros, o que vai ao encontro da resolução $n^{\circ} 307 / 2002$ do conselho Nacional do Meio Ambiente (CONAMA).

PalaVRas Chave: Resíduos de Construção e Demolição; Agregados Reciclados de Concreto; Meio Ambiente.

Urban sprawl and the dense celibacy of medium and large cities have been fraught with difficulties in the disposal of the large volume of waste generated by privatized construction, renovation and demolition activities, in addition to public construction and adaptation to look for more expressive solutions to manage the problem. In order to be recycled compared to other components, however, the number of studies conducted in Brazil is very small, making it difficult to use this material in structural dosages. In principle, development is a theoretical and experimental method aimed at minimizing the impact caused by the environment and characterizing properties such as aggregate and recycled concrete ; The theoretical theory explores aspects for generation, deposition, recovery processes, crushing, practical cases, concrete removal and the existing normative needs. In the experimental development, the influence of the period between molding and recycling on aggregate and concrete properties was analyzed. The results were recycled after generation, positively contributed to the mechanical properties of concrete, due to the large amount of unhydrated particles of concrete for compression and tensile when compared to concrete. natural aggregates. Thus, the research is a viability of the reuse of recycled concrete and mixed aggregate, through the analysis of laboratory test results, based on a household indexation research, also aiming at concrete mechanics, the CW (Construction Waste) is suitable to convert the natural aggregates of concrete. The evaluation of the making of the annual basis in the implementation of concrete, may be determined, and the evaluation of the resolution of 307/2002 (CONAMA).

KEYWORDS: Construction and Demolition Waste; Recycled Concrete; Environmental Aggregates.

\section{Introdução}

Atualmente, com a preocupação ambiental, a sustentabilidade do nosso planeta e com as gerações futuras, se faz necessária a tomadade consciência quanto a buscar novas maneiras de preservar o meio ambiente, buscando diminuir a extração de recursos naturais, para amenizar os impactos gerados pela ocupação acelerada desordenada dos centros urbanos e crescimento populacional.

A preocupação com resíduos de maneira geral é relativamente recente no Brasil, diferente de países como os EUA onde no final da década de 1960 já existia uma política para resíduos, chamada de Resource Conservationand Recovering Act. (CLINTON, 1993)

Estes são considerados serviços essenciais de interesse público, devido à sua importância para a vida. Estes devem ser prestados pelo poder público de forma a garantir a sua universalidade, qualidade, equidade, remuneração módica, controle e participação social (DOLCI 2002a).

Governos municipais e as empresas tem-se a dificuldade e em criar mecanismos de gerenciamento eficazes, capazes de: 
Nortear um uso mais inteligente dos materiais nas frentes de trabalho, visando com isso uma redução no volume de material a ser descartado mais tarde;

Contribuir com a segregação desses resíduos in loco, de modo a facilitar o seu reuso posterior;

Realizar e controlar a disposição do que não pode ser submetido a processos de reciclagem ou reuso direto em locais apropriados, diminuindo com isso o surgimento de áreas clandestinas de bota-fora, que ocorrem em muitas vezes em áreas de preservação ambiental (OLIVEIRA, 2005).

A construção civil é uma das indústrias que mais utiliza recursos naturais, atualmente esta indústria é responsável por cerca de 20\% a 50\% dos recursos extraídos da natureza

Considerando que $13 \%$ das cidades brasileiras pesquisadas no censo de saneamento possuem aterros sanitários, $7 \%$ possuem aterros especiais e que, apenas, $5 \%$ possuem usinas de reciclagem (IBGE, 2000), deve-se propor e implementar métodos de tratamento de resíduos.

No Brasil onde $90 \%$ dos resíduos gerados pelas obras são passíveis de reciclagem, o ideal seria se a reutilização e reciclagem dos resíduos na obra fossem prática constante e incorporada ao dia-a-dia das construtoras como parte integrante do planejamento e execução das obras

A construção civil também possui o maior potencial de consumo de RCD (Resíduos de Construção e Demolição) provenientes de outras indústrias, como cinzas volantes, escórias de alto-forno, sílica ativa (na produção de cimentos, concretos e argamassas); papel reciclado na produção de gesso acartonado; pneus.

Os Resíduos de Construção e Demolição - RCD, também denominados como entulho, tem se tornado um dos alvos do meio técnico-científico, utilizando o mesmo como agregado para inúmeros usos na construção civil e também na pavimentação rodoviária, entrando como substituto às matérias-primas hoje utilizadas nestes setores (CARNEIRO, 2001).

Praticamente todas as atividades desenvolvidas no setor da construção civil são geradoras de entulho. No processo construtivo, o alto índice de perdas do setor é a principal causa do entulho gerado. A quantidade de entulho gerado corresponde, em média, a $50 \%$ do material desperdiçado.

\section{Metodologia}

Para quantificar a geração dos Resíduos da Construção Civil produzidos no município de Resende, tem como base o cálculo do movimento das cargas transportadas pelas empresas legalizadas para o transporte de RCC no município.

Os dados para esse cálculo foram extraídos junto às empresas em pesquisa de fonte própria. Levamos em consideração os seguintes aspectos:

- A quantidade de empresas que atuam no setor;

- $\quad$ A capacidade de transporte de cada empresa; 
Para a estimativa da geração dos RCC transportados pelas empresas, adotou-se uma massa específica de $1.200 \mathrm{~kg} / \mathrm{m}^{3}$.

Foi considerado ainda a capacidade de $5 \mathrm{~m}^{3}$ de cada caçamba, e que as empresas fornecem 80 \% de suas caçambas mensalmente, sendo que, cada uma delas pode ficar em um local em torno de 03 dias. *Sendo assim estima-se que uma caçamba pode-se "locada" 10 (dez) vezes por mês.

Tabela 1 - Estimativa de Geração de RCC/RDC Município de Resende

\begin{tabular}{|c|c|c|c|c|c|}
\hline EMPRESA & $\begin{array}{c}\text { No DE } \\
\text { CAÇAMBAS }\end{array}$ & $\begin{array}{c}\text { TOTAL DE } \\
\text { CAÇAMBAS } \\
\text { ESTIMADAS } \\
\text { POR MÊS }\end{array}$ & $\begin{array}{c}\text { VALOR } \\
\text { TOTAL DE } \\
\text { LOCAÇÃO } \\
\text { POR MÊS }\end{array}$ & $\begin{array}{c}\text { VOLUME } \\
\text { MÉDIO DE } \\
\text { CAÇAMBAS } \\
\mathbf{( m}^{\mathbf{3}} \mathbf{)}\end{array}$ & $\begin{array}{c}\text { CAPACIDADE DE } \\
\text { COLETA } \\
\text { MESALMENTE } \\
\mathbf{( m}^{\mathbf{3}} \mathbf{)}\end{array}$ \\
\hline A & 48 & 38 & 380 & 5 & 1.900 \\
\hline B & 100 & 80 & 800 & 5 & 4.000 \\
\hline C & 20 & 16 & 160 & 5 & 800 \\
\hline D & 50 & 40 & 400 & 5 & 2.000 \\
\hline
\end{tabular}

Fonte: Pesquisa de Campo, 2015.

Sendo assim estima-se que o número de caçambas contratadas mensalmente é de 174 caçambas/mês e o volume médio das caçambas é de $5 \mathrm{~m}^{3}$, obtém-se, portanto, um volume médio de RCC de $8.700 \mathrm{~m}^{3} / \mathrm{mês}$, que equivale a $290 \mathrm{~m}^{3} /$ dia.

Adotando-se uma massa específica dos RCC de $1.200 \mathrm{~kg} / \mathrm{m}^{3}$ teremos uma geração de 10.440 t/mês ou 348 t/dia,considerando a população estimada 125.214 habitantes de acordo com o (Censo de 2010 do IBGE), avalia-se que o valor de geração de RCC é de 2,78 kg/hab/dia ou $1.014,70 \mathrm{~kg} / \mathrm{hab} / \mathrm{ano}$.

A deposição irregular dos RCC é o principal problema a ser enfrentado em relação ao saneamento, no ambiente urbano, já que esses resíduos provocam a proliferação de vetores nocivos à saúde, enchentes, interdição parcial de vias e degradação do ambiente urbano.

Dentre as principais consequências, o custo de remoção de resíduos irregularmente depositados é imenso aos cofres públicos. A prefeitura de São Paulo, por exemplo, recolhe, diariamente, 4.000 (quatro mil) toneladas de resíduos da construção civil, a um custo mensal de $\mathrm{R} \$ 4,5$ milhões.( SÃO PAULO - SP, 2012)

As vantagens econômicas da reciclagem, em substituição às deposições irregulares de 
RCC, apresentam-se claramente nos custos de limpeza urbana para as administrações municipais. Os custos com descarte irregular, correção da deposição com aterramento e

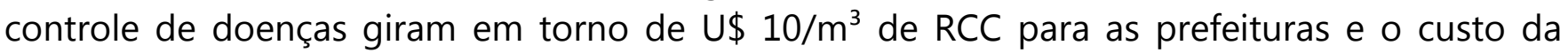
reciclagem corresponde a $25 \%$ desse valor (CARNEIRO, 2001).

As vantagens sociais da reciclagem de RCC traduzem-se no emprego dos materiais reciclados em programas de habitação popular e de infraestrutura urbanos, com a criação de empregos diretos e indiretos (CARNEIRO, 2001).

Reciclar o entulho - independente do uso que a ele for dado - representa vantagens econômicas, sociais e ambientais, tais como:

- Economia na aquisição de matéria-prima, devido a substituição de materiais convencionais, pelo entulho;

- Diminuição da poluição gerada pelo entulho e de suas consequências negativas como enchentes e assoreamento de rios e córregos, e preservação das reservas naturais de matériaprima;

- $\quad$ Preservação das reservas minerais não renováveis;

- Preservação e redução de áreas de aterros de inertes, minimizando os impactos decorrentes da deposição maciça de RCC;

- Criação de alternativa para as mineradoras, cada vez mais sujeitas às restrições ambientais;

- $\quad$ Redução do consumo de energia e de geração de CO2 na produção e no transporte de materiais.

\section{Resultados}

\section{I. Classificações dos RCC}

O Conselho Nacional do Meio Ambiente (CONAMA) existe para assessorar, estudar e propor ao Governo, as linhas de direção que devem tomar as políticas governamentais para a exploração e preservação do meio ambiente e dos recursos naturais.

Conforme Resolução 307 do Conama, de 05/07/2002, artigo terceiro, os RCC são caracterizados em quatro classes:

CLASSE A - São os resíduos reutilizáveis ou recicláveis como agregados, tais como de construção, demolição, reformas e reparos de pavimentação. Exemplos: cacos de cerâmica, tijolos, blocos, telhas, placas de revestimento, concreto, argamassa, entre outros.

CLASSE B - São os resíduos recicláveis para outras destinações, tais como: plástico, madeira, papel, papelão, metais, vidro e outros. 
CLASSE C - São os resíduos em que não foram desenvolvidas tecnologias ou aplicações economicamente viáveis que permitam a sua reciclagem, ou recuperação, tais como os produtos oriundos do gesso.

CLASSE D - São resíduos perigosos, oriundos do processo de construção, tais como: tintas, solventes, óleos e outros, ou aqueles contaminados oriundos de demolições, reformas e reparos de clínicas radiológicas, instalações industriais e outros.

O CONAMA também estabelece as diretrizes para a destinação ou reutilização adequada de cada material, no entanto existe um grande déficit das empresas e dos municípios para aplicação deste. Conforme apresentado na tabela 3 a Resolução 307/2002 estabelece que:

A seguir a Tabela 3 explica sobre as classes dos resíduos referentes a sua reutilização e reciclagem, com o objetivo de especificá-los de uma forma mais direta dentro dos materiais de Classes A e B.

Figura 1 - Reutilização e Reciclagem Adequada de RCC

\begin{tabular}{|ll|}
\hline \multicolumn{1}{|c|}{ Residuo } & \multicolumn{1}{c|}{ Reutilização e Reciclagem } \\
\hline Resíduos Classe A & $\begin{array}{l}\text { Reutilização ou processamento como agregado reciclado e aplicação } \\
\text { como enchimento de valas, aterros, revestimento primário de vias } \\
\text { de terra (cascallhamento), camadas de pavimento, passeiose muros, } \\
\text { artefatos, drenagem urbana, confeç̧ão de blocos, meios-fios, etc. }\end{array}$ \\
\hline $\begin{array}{l}\text { Resíduos Classe B: } \\
\text { plásticos, metais, vidros, } \\
\text { papel e papelão }\end{array}$ & $\begin{array}{l}\text { Processamento de reciclagem que permite o uso do resíduo como } \\
\text { matéria-prima de um novo processo produtivo. }\end{array}$ \\
\hline Resíduo Classe B: madeir a & $\begin{array}{l}\text { Reutilização ou reciclagem da madeira a partir de mecanismos de } \\
\text { logistica reversa, queima para a geração de energia, confecção de } \\
\text { baias, placas de sinalização e outras utilidades. }\end{array}$ \\
\hline Resíduos Classe B: gesso & $\begin{array}{l}\text { Reciclagem do gesso a partir de mecanismos de logística reversa ou } \\
\text { parcerias com indústrias que utilizam o gesso e seus componentes } \\
\text { como insumos e na agricultura. }\end{array}$ \\
\hline
\end{tabular}

Fonte: SÃO PAULO e SindusCon-SP, 2012.

\section{III.I.II. Reciclagem dos RCC}

Para obter os materiais beneficiados oriundos da reciclagem dos RCC, as usinas devem desenvolver algumas atividades. Após a chegada dos resíduos, a primeira etapa de processamento consiste em avaliar e separar manualmente os materiais não recicláveis do entulho de construção, materiais como plásticos, metais, papel, papelão, trapos, entre outros.

Após a separação, o material é limpo para que possa abastecer os moinhos. Durante o processo é realizada separação magnética de metais e empilhamento do material moído. 
Os moinhos podem ser de mandíbula, mais rápidos e rústicos, ou de bola, mais lentos, porém com moagem mais intensa e custos mais altos.

As usinas de reciclagem geralmente utilizam equipamentos com maior capacidade, como, por exemplo, britadores primários de impacto, capazes de determinar as dimensões máximas dos agregados. Esses equipamentos conseguem granulométricas diferentes a partir de sua regulagem (ZORDAN, 1997).

\section{I.III. Agregado Miúdo}

A mineração de areia, é uma atividade economicamente importante ao país principalmente porque oferece materiais para a indústria e construção civil. A areia obtida da extração pode ser usada para fundição, fabricação de vidros, silicatos, cerâmicas, construção de campos esportivos, filtragens, entre outras, o que implica em seu grande volume de extração.

Porém a mineração, mesmo regulamentada, pode causar impactos ambientais, entre os quais destacam-se:

- $\quad$ Destruição da mata ciliar com a instalação da mineradora, e com isso a alteração dos cursos dos rios e o seu assoreamento;

- Compactação do solo causada pela retirada da mata e o trânsito de máquinas;

- $\quad$ Erosão do solo, já que o mesmo foi degradado e desprotegido com a retirada das árvores;

- $\quad$ Fuga da fauna como consequência do barulho e movimentação no local;

- $\quad$ Poluição das águas e dos solos com o uso inadequado de combustíveis fósseis;

- Queimadas.

A mineração de areia, embora necessária, altera a paisagem do lugar minerado e degrada o meio ambiente, por isso, é recomendável desenvolver ações para minimizar seus impactos e restaurar a área degradada.

A substituição gradativa do agregado miúdo natural (areia) por agregado miúdo reciclado de concreto tem como principal objetivo a análise do comportamento destas famílias de concreto tanto em seu estado fresco como no estado endurecido, buscando-se assim uma relação entre as características a serem analisadas com a proporção dos materiais utilizados na confecção dos referidos traços e com isso embasar a determinação do teor de substituição tido como ótimo, ou seja, teor de substituição que apresente as melhores correlações entre as propriedades do concreto tanto em seu estado fresco como no estado endurecido.

O incremento utilizado para substituição do agregado miúdo natural é de $20 \%$ até se atingir o limite de $100 \%$ de substituição do mesmo. Portanto, são confeccionados 5 traços utilizando-se agregado miúdo reciclado de concreto em crescentes teores $(20 \%, 40 \%, 60 \%$, $80 \%$ e $100 \%$ ), sendo que para tais traços mantiveram-se fixos os parâmetros de dosagem do traço de referência, variando-se apenas o consumo de superplastificante 
A tabela 04 apresenta os dados referentes à confecção dos traços com teores crescentes de substituição do agregado miúdo por agregado reciclado de concreto e as respectivas propriedades do concreto em seu estado fresco.

Tabela 2 - Dados referentes à confecção dos traços de teores crescentes de substituição do agregado miúdo e as respectivas propriedades do concreto fresco

\begin{tabular}{|c|c|c|c|c|c|c|}
\hline \multicolumn{2}{|c|}{ Traço 1:m = 1:4,52 } & $\begin{array}{l}20 \% \text { de } \\
\text { Resíduo }\end{array}$ & $\begin{array}{l}40 \% \text { de } \\
\text { Resíduo }\end{array}$ & $\begin{array}{l}60 \% \text { de } \\
\text { Resíduo }\end{array}$ & $\begin{array}{l}80 \% \text { de } \\
\text { Resíduo }\end{array}$ & $\begin{array}{l}\text { 100\% de } \\
\text { Resíduo }\end{array}$ \\
\hline \multirow{8}{*}{$\begin{array}{l}\text { Dados da } \\
\text { Dosagem }\end{array}$} & Teor de Argamassa (\%) & 53 & 53 & 53 & 53 & 53 \\
\hline & $\begin{array}{c}\text { Consumo de Cimento } \\
\left(\mathrm{kg} / \mathrm{m}^{3}\right)\end{array}$ & 469,5 & 469,5 & 469,5 & 469,5 & 469,5 \\
\hline & $\begin{array}{c}\begin{array}{c}\text { Consumo de Água } \\
\left(\mathrm{kg} / \mathrm{m}^{3}\right)\end{array} \\
\end{array}$ & 166,7 & 166,7 & 166,7 & 166,7 & 166,7 \\
\hline & $\begin{array}{c}\text { Consumo de Areia } \\
\left(\mathrm{kg} / \mathrm{m}^{3}\right)\end{array}$ & 723,2 & 542,4 & 361,6 & 180,8 & 0 \\
\hline & $\begin{array}{c}\text { Consumo de Resíduo } \\
\left(\mathrm{kg} / \mathrm{m}^{3}\right)\end{array}$ & 180,8 & 361,6 & 542,4 & 723,2 & 904 \\
\hline & $\begin{array}{c}\text { Consumo de Brita } \\
\left(\mathrm{kg} / \mathrm{m}^{3}\right)\end{array}$ & 1218 & 1218 & 1218 & 1218 & 1218 \\
\hline & Relação a/c (kg/kg) & 0,355 & 0,355 & 0,355 & 0,355 & 0,355 \\
\hline & $\begin{array}{c}\text { Consumo de } \\
\text { Superplastificante (\% } \\
\text { sobre a massa de } \\
\text { cimento) }\end{array}$ & 0,5 & 0,6 & 0,8 & 1,1 & 1,4 \\
\hline \multirow{4}{*}{$\begin{array}{l}\text { Propriedades } \\
\text { do Concreto } \\
\text { Fresco }\end{array}$} & Slump (cm) & 18,1 & 16,2 & 18 & 17,8 & 17,5 \\
\hline & Temperatura $\left({ }^{\circ} \mathrm{C}\right)$ & 25,1 & 25,7 & 26,7 & 27 & 26,1 \\
\hline & ArIncorporado (\%) & 4 & 3,9 & 3,7 & 4 & 2,5 \\
\hline & $\begin{array}{c}\text { DensidadeAparente } \\
\left(t / \mathrm{m}^{3}\right)\end{array}$ & 2,486 & 2,496 & 2,503 & 2,484 & 2,514 \\
\hline
\end{tabular}

Fonte: SIMIELE, 2010.

Os procedimentos para moldagem dos corpos-de-prova são embasados na norma NBR NM 67 (ABNT, 1998), sendo estes desmoldados após 24 horas e levados para cura em câmara úmida até atingirem a idade de ruptura, já as peças de concreto retangulares são moldadas com o auxílio da mesa vibratória e utilizando-se moldes de PVC, sendo estas desmoldadas e curadas de maneira análoga aos corpos-de-prova cilíndricos. Logo abaixo, a tabela 5 demonstrará em cada ocasião (Ensaio), o número de corpos-de-prova que são gerados em cada teste e a idade em que foi ensaiado. 
Tabela 3 - PPC e corpos de prova moldados e os respectivos ensaios a que foram submetidos

\begin{tabular}{|c|c|c|c|}
\hline Traço & Ensaio & $\begin{array}{c}\mathrm{n}^{\circ} \text { de Corpos-de-prova / } \\
\text { PPC }\end{array}$ & $\begin{array}{l}\text { Idade a que } \\
\text { foi ensaiado }\end{array}$ \\
\hline \multirow{11}{*}{ Referência } & \multirow{2}{*}{ Desgaste por abrasão } & 2 corpos-de-prova & 7 dias \\
\hline & & 2 corpos-de-prova & 28 dias \\
\hline & Absorção por Imersão & 3 corpos-de-prova & 28 dias \\
\hline & \multirow{2}{*}{$\begin{array}{c}\text { Compressão Axial em Peça } \\
\text { Retangular de } 6 \mathrm{~cm} \text { de } \\
\text { espessura }\end{array}$} & 4 peças & 7 dias \\
\hline & & 4 peças & 28 dias \\
\hline & \multirow{2}{*}{$\begin{array}{c}\text { Compressão Axial em Peça } \\
\text { Retangular de } 3 \mathrm{~cm} \text { de } \\
\text { espessura }\end{array}$} & 4 peças & 7 dias \\
\hline & & 4 peças & 28 dias \\
\hline & \multirow{2}{*}{$\begin{array}{c}\text { Compressão Axial em Peça } \\
\text { Hexagonal de } 6 \mathrm{~cm} \text { de } \\
\text { espessura }\end{array}$} & 4 peças & 7 dias \\
\hline & & 4 peças & 28 dias \\
\hline & \multirow{2}{*}{$\begin{array}{c}\text { Compressão Axial em Peça } \\
\text { Hexagonal de } 3 \mathrm{~cm} \text { de } \\
\text { espessura }\end{array}$} & 4 peças & 7 dias \\
\hline & & 4 peças & 28 dias \\
\hline \multirow{11}{*}{$\begin{array}{l}60 \% \text { de } \\
\text { Resíduo }\end{array}$} & \multirow{2}{*}{ Desgaste por abrasão } & 2 corpos-de-prova & 7 dias \\
\hline & & 2 corpos-de-prova & 28 dias \\
\hline & Absorção por Imersão & 3 corpos-de-prova & 28 dias \\
\hline & \multirow{2}{*}{$\begin{array}{c}\text { Compressão Axial em Peça } \\
\text { Retangular de } 6 \mathrm{~cm} \text { de } \\
\text { espessura }\end{array}$} & 4 peças & 7 dias \\
\hline & & 4 peças & 28 dias \\
\hline & \multirow{2}{*}{$\begin{array}{c}\text { Compressão Axial em Peça } \\
\text { Retangular de } 3 \mathrm{~cm} \text { de } \\
\text { espessura }\end{array}$} & 4 peças & 7 dias \\
\hline & & 4 peças & 28 dias \\
\hline & \multirow{2}{*}{$\begin{array}{c}\text { Compressão Axial em Peça } \\
\text { Hexagonal de } 6 \mathrm{~cm} \text { de } \\
\text { espessura }\end{array}$} & 4 peças & 7 dias \\
\hline & & 4 peças & 28 dias \\
\hline & \multirow{2}{*}{$\begin{array}{c}\text { Compressão Axial em Peça } \\
\text { Hexagonal de } 3 \mathrm{~cm} \text { de } \\
\text { espessura }\end{array}$} & 4 peças & 7 dias \\
\hline & & 4 peças & 28 dias \\
\hline
\end{tabular}

Fonte: SIMIELE, 2010.

Para todos os 5 traços confeccionados são moldados 3 corpos-de-prova cilíndricos (10 $\mathrm{cm}$ de diâmetro por $20 \mathrm{~cm}$ de altura) para cada uma das idades de 7, 28, 56 e 120 e 3 peças de concreto retangulares $(20 \mathrm{~cm}$ de comprimento por $10 \mathrm{~cm}$ de largura e $6 \mathrm{~cm}$ de altura) para a idade de 28 dia, sendo estes destinados aos ensaios de compressão axial (determina a compressão nos extremos de uma base ("empurra" as extremidades)). Serão mostrados nas tabelas a seguir os testes realizados com os teores de agregados de $20 \%$ até $100 \%$, além do traço de referência.

As tabelas a seguir na próxima página, mostram as vantagens em reaproveitar os resíduos em função da confecção de um futuro material para a construção mais eficiente e com características melhores em relação a materiais comuns. 
Tabela 4 - Resultado do ensaio de compressão axial para o traço de referência

\begin{tabular}{|c|c|c|c|c|c|c|c|}
\hline \multirow{13}{*}{$\begin{array}{l}\text { Traço de } \\
\text { Referência }\end{array}$} & $\begin{array}{l}\text { Idade de } \\
\text { Ruptura }\end{array}$ & $\begin{array}{l}\text { Corpo- } \\
\text { de-Prova }\end{array}$ & $\begin{array}{l}\text { Carga de } \\
\text { Ruptura } \\
\text { (ton.) }\end{array}$ & $\begin{array}{l}\text { Resistência à } \\
\text { Compressão } \\
\text { Axial (Mpa) }\end{array}$ & $\begin{array}{l}\text { Valor } \\
\text { Médio } \\
\text { (Mpa) }\end{array}$ & $\begin{array}{l}\text { DesvioPadrão } \\
\text { (Mpa) }\end{array}$ & $\begin{array}{l}\text { Coeficiente } \\
\text { de Variação } \\
\text { (\%) }\end{array}$ \\
\hline & \multirow{3}{*}{7 dias } & 1 & 28,3 & 36,1 & \multirow{3}{*}{35,9} & \multirow{3}{*}{1,4} & \multirow{3}{*}{3,8} \\
\hline & & 2 & 29,4 & 37,4 & & & \\
\hline & & 3 & 26,8 & 34,1 & & & \\
\hline & \multirow{3}{*}{28 dias } & 1 & 35,3 & 44,9 & \multirow{3}{*}{45,8} & \multirow{3}{*}{0,8} & \multirow{3}{*}{1,8} \\
\hline & & 2 & 35,8 & 45,6 & & & \\
\hline & & 3 & 36,9 & 46,9 & & & \\
\hline & \multirow{3}{*}{56 dias } & 1 & 37,3 & 47,5 & \multirow{3}{*}{49,2} & \multirow{3}{*}{1,4} & \multirow{3}{*}{2,8} \\
\hline & & 2 & 38,8 & 49,4 & & & \\
\hline & & 3 & 39,9 & 50,8 & & & \\
\hline & \multirow{3}{*}{120 dias } & 1 & 41,5 & 52,8 & \multirow{3}{*}{53,1} & \multirow{3}{*}{0,9} & \multirow{3}{*}{1,7} \\
\hline & & 2 & 42,5 & 54,1 & & & \\
\hline & & 3 & 41,1 & 52,3 & & & \\
\hline
\end{tabular}

Fonte: SIMIELE, 2010.

Tabela 5 - Resultado do ensaio de compressão axial para o traço com adição de $20 \%$ de agregado reciclado de concreto

\begin{tabular}{|c|c|c|c|c|c|c|c|}
\hline \multirow{13}{*}{$\begin{array}{c}\text { Traço com } \\
\text { Teor de } \\
20 \% \text { de } \\
\text { Agregado } \\
\text { Reciclado }\end{array}$} & $\begin{array}{l}\text { Idade de } \\
\text { Ruptura }\end{array}$ & $\begin{array}{l}\text { Corpo- } \\
\text { de-Prova }\end{array}$ & $\begin{array}{c}\text { Carga de } \\
\text { Ruptura } \\
\text { (ton.) } \\
\end{array}$ & $\begin{array}{l}\text { Resistência à } \\
\text { Compressão } \\
\text { Axial (Mpa) }\end{array}$ & $\begin{array}{l}\text { Valor } \\
\text { Médio } \\
\text { (Mpa) } \\
\end{array}$ & $\begin{array}{l}\text { DesvioPadrão } \\
\text { (Mpa) }\end{array}$ & $\begin{array}{c}\text { Coeficiente } \\
\text { de Variação } \\
\text { (\%) }\end{array}$ \\
\hline & \multirow{3}{*}{7 dias } & 1 & 29,9 & 38,1 & \multirow{3}{*}{41,1} & \multirow{3}{*}{2,3} & \multirow{3}{*}{5,5} \\
\hline & & 2 & 32,7 & 41,6 & & & \\
\hline & & 3 & 34,2 & 43,5 & & & \\
\hline & \multirow{3}{*}{28 dias } & 1 & 38,4 & 48,9 & \multirow{3}{*}{46,3} & \multirow{3}{*}{2,0} & \multirow{3}{*}{4,4} \\
\hline & & 2 & 34,5 & 43,9 & & & \\
\hline & & 3 & 36,1 & 46,0 & & & \\
\hline & \multirow{3}{*}{56 dias } & 1 & 34,0 & 45,5 & \multirow{3}{*}{48,7} & \multirow{3}{*}{2,3} & \multirow{3}{*}{4,7} \\
\hline & & 2 & 38,0 & 49,8 & & & \\
\hline & & 3 & 38,0 & 50,7 & & & \\
\hline & \multirow{3}{*}{120 dias } & 1 & 44,0 & 56,0 & \multirow{3}{*}{53,9} & \multirow{3}{*}{1,9} & \multirow{3}{*}{3,5} \\
\hline & & 2 & 41,1 & 52,3 & & & \\
\hline & & 3 & 41,9 & 53,3 & & & \\
\hline
\end{tabular}

Fonte: SIMIELE, 2010.

Tabela 6 - Resultado do ensaio de compressão axial para o traço com adição de $40 \%$ de agregado reciclado de concreto

\begin{tabular}{|c|c|c|c|c|c|c|c|}
\hline \multirow{5}{*}{$\begin{array}{c}\text { Traço com } \\
\text { Teor de } \\
40 \% \text { de } \\
\text { Agregado } \\
\text { Reciclado }\end{array}$} & $\begin{array}{l}\text { Idade de } \\
\text { Ruptura }\end{array}$ & $\begin{array}{l}\text { Corpo- } \\
\text { de-Prova }\end{array}$ & $\begin{array}{c}\text { Carga de } \\
\text { Ruptura } \\
\text { (ton.) }\end{array}$ & $\begin{array}{l}\text { Resistência à } \\
\text { Compressão } \\
\text { Axial (Mpa) } \\
\end{array}$ & $\begin{array}{l}\text { Valor } \\
\text { Médio } \\
\text { (Mpa) } \\
\end{array}$ & $\begin{array}{l}\text { DesvioPadrão } \\
\text { (Mpa) }\end{array}$ & $\begin{array}{c}\text { Coeficiente } \\
\text { de Variação } \\
(\%)\end{array}$ \\
\hline & \multirow{3}{*}{7 dias } & 1 & 33,5 & 42,7 & \multirow{3}{*}{45,4} & \multirow{3}{*}{2,2} & \multirow{3}{*}{4,9} \\
\hline & & 2 & 35,6 & 45,3 & & & \\
\hline & & 3 & 37,8 & 48,1 & & & \\
\hline & 28 dias & 1 & 34,2 & 43,5 & 47,7 & 3,0 & 6,4 \\
\hline
\end{tabular}




\begin{tabular}{|c|c|c|c|c|c|c|}
\hline & 2 & 39,8 & 50,7 & & & \\
\hline & 3 & 38,4 & 48,9 & & & \\
\hline \multirow{3}{*}{56 dias } & 1 & 38,6 & 49,1 & \multirow{3}{*}{49,3} & \multirow{3}{*}{3,4} & \multirow{3}{*}{6,9} \\
\hline & 2 & 42,0 & 53,5 & & & \\
\hline & 3 & 35,5 & 45,2 & & & \\
\hline \multirow{3}{*}{120 dias } & 1 & 41,5 & 52,8 & \multirow{3}{*}{54,2} & \multirow{3}{*}{1,9} & \multirow{3}{*}{3,4} \\
\hline & 2 & 44,2 & 56,3 & & & \\
\hline & 3 & 41,9 & 53,3 & & & \\
\hline
\end{tabular}

Fonte: SIMIELE, 2010.

Tabela 7 - Resultado do ensaio de compressão axial para o traço com adição de $60 \%$ de agregado reciclado de concreto

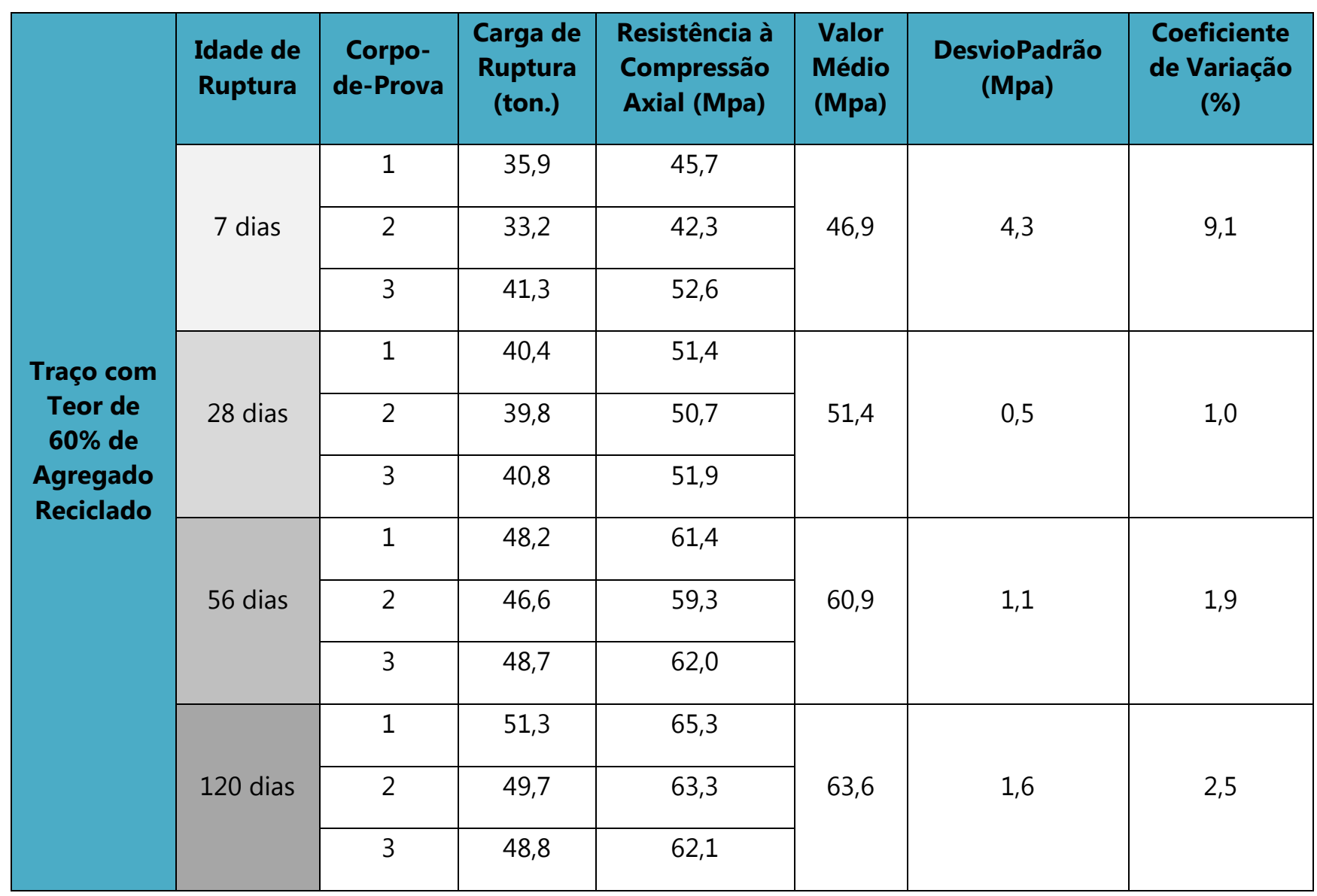

Fonte: SIMIELE, 2010.

Tabela 8 - Resultado do ensaio de compressão axial para o traço com adição de $80 \%$ de agregado reciclado de concreto

\begin{tabular}{|c|c|c|c|c|c|c|c|}
\hline $\begin{array}{c}\text { Traço com } \\
\text { Teor de } \\
\mathbf{8 0} \% \text { de }\end{array}$ & $\begin{array}{c}\text { Idade de } \\
\text { Ruptura }\end{array}$ & $\begin{array}{c}\text { Corpo- } \\
\text { de-Prova }\end{array}$ & $\begin{array}{c}\text { Carga de } \\
\text { Ruptura } \\
\text { (ton.) }\end{array}$ & $\begin{array}{c}\text { Resistência à } \\
\text { Compressão } \\
\text { Axial (Mpa) }\end{array}$ & $\begin{array}{c}\text { Valor } \\
\text { Médio } \\
\text { (Mpa) }\end{array}$ & $\begin{array}{c}\text { DesvioPadrão } \\
\text { (Mpa) }\end{array}$ & $\begin{array}{c}\text { Coeficiente } \\
\text { de Variação } \\
\text { (\%) }\end{array}$ \\
\cline { 2 - 4 } & 7 dias & 1 & 40,0 & 50,9 & 50,8 & 0,9 & 1,9 \\
\hline
\end{tabular}




\begin{tabular}{|c|c|c|c|c|c|c|c|}
\hline \multirow[t]{11}{*}{ Reciclado } & & 2 & 38,9 & 49,5 & & & \\
\hline & & 3 & 40,7 & 51,8 & & & \\
\hline & \multirow{3}{*}{28 dias } & 1 & 48,7 & 62,0 & \multirow{3}{*}{57,4} & \multirow{3}{*}{3,9} & \multirow{3}{*}{6,8} \\
\hline & & 2 & 41,2 & 52,5 & & & \\
\hline & & 3 & 45,4 & 57,8 & & & \\
\hline & \multirow{3}{*}{56 dias } & 1 & 45,0 & 57,3 & \multirow{3}{*}{59,6} & \multirow{3}{*}{1,9} & \multirow{3}{*}{3,2} \\
\hline & & 2 & 48,7 & 62,0 & & & \\
\hline & & 3 & 46,8 & 59,6 & & & \\
\hline & \multirow{3}{*}{120 dias } & 1 & 49,2 & 62,6 & \multirow{3}{*}{63,0} & \multirow{3}{*}{0,9} & \multirow{3}{*}{1,5} \\
\hline & & 2 & 48,9 & 62,3 & & & \\
\hline & & 3 & 50,3 & 64,0 & & & \\
\hline
\end{tabular}

Fonte: SIMIELE, 2010.

Tabela 9 - Resultado do ensaio de compressão axial para o traço com adição de $100 \%$ de agregado reciclado de concreto

\begin{tabular}{|c|c|c|c|c|c|c|c|}
\hline \multirow{13}{*}{$\begin{array}{l}\text { Traço com } \\
\text { Teor de } \\
100 \% \text { de } \\
\text { Agregado } \\
\text { Reciclado }\end{array}$} & $\begin{array}{l}\text { Idade de } \\
\text { Ruptura }\end{array}$ & $\begin{array}{l}\text { Corpo- } \\
\text { de-Prova }\end{array}$ & $\begin{array}{c}\text { Carga de } \\
\text { Ruptura } \\
\text { (ton.) }\end{array}$ & $\begin{array}{l}\text { Resistência à } \\
\text { Compressão } \\
\text { Axial (Mpa) }\end{array}$ & $\begin{array}{l}\text { Valor } \\
\text { Médio } \\
\text { (Mpa) }\end{array}$ & $\begin{array}{l}\text { DesvioPadrão } \\
\text { (Mpa) }\end{array}$ & $\begin{array}{l}\text { Coeficiente } \\
\text { de Variação } \\
\text { (\%) }\end{array}$ \\
\hline & \multirow{3}{*}{7 dias } & 1 & 39,7 & 50,5 & \multirow{3}{*}{51,5} & \multirow{3}{*}{1,0} & \multirow{3}{*}{1,9} \\
\hline & & 2 & 40,2 & 51,2 & & & \\
\hline & & 3 & 41,5 & 52,8 & & & \\
\hline & \multirow{3}{*}{28 dias } & 1 & 48,3 & 61,5 & \multirow{3}{*}{57,4} & \multirow{3}{*}{3,9} & \multirow{3}{*}{1,2} \\
\hline & & 2 & 47,3 & 60,2 & & & \\
\hline & & 3 & 46,9 & 59,7 & & & \\
\hline & \multirow{3}{*}{56 dias } & 1 & 47,0 & 59,8 & \multirow{3}{*}{62,0} & \multirow{3}{*}{1,9} & \multirow{3}{*}{3,0} \\
\hline & & 2 & 48,5 & 61,8 & & & \\
\hline & & 3 & 50,6 & 64,4 & & & \\
\hline & \multirow{3}{*}{120 dias } & 1 & 51,0 & 64,9 & \multirow{3}{*}{64,5} & \multirow{3}{*}{1,0} & \multirow{3}{*}{1,5} \\
\hline & & 2 & 49,8 & 63,4 & & & \\
\hline & & 3 & 51,2 & 65,2 & & & \\
\hline
\end{tabular}

Fonte: SIMIELE, 2010.

\section{Considerações Finais}

Diante dos estudos avaliados o reaproveitamento dos resíduos das indústrias de construções civil, como substituição parcial dos agregados normais, na produção do concreto, pode-se concluir que os resultados esperados foram atingidos de forma satisfatória.

Através dos estudos confirmou-se a potencialidade da utilização dos agregados reciclados para produção de concreto, minimizando os impactos ambientais além de agregar valor ao resíduo. A utilização dos agregados reciclados, substituindo parcialmente os agregados normais, para a confecção de blocos, atende satisfatoriamente as legislações vigentes. Contudo, observa-se a necessidade de mais pesquisas voltadas para avaliar o comportamento destes resíduos, principalmente por se tratar de um novo material. Desta forma, recomenda-se o desenvolvimento de outros estudos no sentido de contribuir para aumentar o conhecimento sobre o assunto. Verificou-se também que este tipo de resíduo 
apresentou um limite de resistência à compressão. Os ensaios mostram que não há alteração no peso específico do material que implica na manutenção do peso próprio das estruturas. $O$ uso do material reciclado evita o uso de recursos não renováveis, logo o uso do concreto ecológico tem base sustentável diante dos resultados dos ensaios. Os benefícios do concreto ecológico são de caráter, ambiental, econômico e principalmente social, pois esse é o objetivo da engenharia, construir utilizando os recursos da natureza de forma consciente visando o bem-estar da sociedade.

\section{Referências}

CONAMA. Conselho Nacional do Meio Ambiente. Resolução No 307, de 5 de Julho de 2002. Estabelece diretrizes, critérios e procedimentos para a gestão dos resíduos da Construção Civil. Disponível em: < http://www.mma.gov.br/port/conama/res/res02/res 30702.html >. Acessoem: 30 de maio de 2009.

CLINTON, Summary of the Resource Conservation and Recovery Act, https://www.epa.gov/lawsregulations/summary-resource-conservation-andrecovery-act, 1993.

DOLCI, Conte ACP. Controle Social. In: Seminário Saneamento: Regulação e os impactos para o consumidor; 9 e 10 de Abril de 2002 a, Rio de Janeiro.[CD ROM].

OLIVEIRA， J. C.; REZENDE， L. R.; GUIMARÃES， R. C.; CAMAPUM, J. C.; SILVA, A. L. A. Evaluation of a flexible pavement executed with recycled aggregates of construction and demolition waste in the municipal district of Goiânia - Goiás. In: 2005 INTERNATIONAL SYMPOSIUM ON PAVEMENT RECYCLING, 2005, São Paulo, Anais eletrônicos do 2005 INTERNATIONAL SYMPOSIUM ON PAVEMENT RECYCLING. [CD ROM]. São Paulo, 2005. n.p.

IBGE, INSTITUTO DE BRASILEIRO DE GEOGAFIA E ESTARÍSTICA. Características da Populoação , Resultados da Amostra, 2000.

SÃO PAULO - SP, GOVERNO DO ESTADO DE SÃO PAU LO SECRETARIA DO MEIO AMBIENTE, Coordenadoria de Planejamento Ambiental, 2002.

ESPINELLI, U. A gestão do consumo de materiais como instrumento para a redução da geração de resíduos nos canteiros de obras. In: Seminário de Gestão e Reciclagem de Resíduos da Construção e
Demolição - Avanços e Desafios. São Paulo. PCC USP, 2005. CDROM. Diniz, M. C. S.; Correia, M. F.; Melo E. C. S.; Farias, W. R. G.; Aragão, M. R. S. 2005 "Importância Relativa de Variáveis Meteorológicas na Formação da Convecção Profunda: Uma Aplicação da Análise Fatorial de ComponentesPrincipais."

SIMIELE, 2010. "ANÁLISE DO GERENCIAMENTO DE RESÍDUOS DE GESSO NO MUNICÍPIO DE SALVADOR-BA".

CARNeiro, A. P; BURGOS, P. C; AlBeRTE, E. P. V. Uso do agregado reciclado em camadas de base e sub-base de pavimentos. Projeto Entulho Bom. Salvador: EDUFBA/ Caixa Econômica Federal, 2001, 188-227 p. Galichio, Wagner, 2007 "Estudo da relaçao ente ozônio e parâmetros meteorológicos na atmosfera de São Paulo".

ZORDAN, S.E. A utilização do entulho como agregado, na confecção do concreto. Campinas. 1997. 140p. Dissertação (Mestrado) - Faculdade de Engenharia Civil, UNICAMP. Disponível em [http://www.reciclagem.pcc.usp.br/entulho_ind_ccivi I.htm]. Acesso em: 27 jul. 2006.Reboita, Michelle; Krusche, Nisia\&Piccoli, Humberto Camargo.2006 "ClimateVariability in Rio Grande, RS, Brazil: A QuantitativeAnalysisofContributionsduetoAtmosphe ric Systems".

SALDIVA, P. H. N. ; III, C. A. P. ; Schwartz, J. ; Dockery, D. W Lichtenfels, Ana Júlia F C ; Salge,J. M. ; Barone, I. A. ; Böhm, György M . 1994 "Air Pollution and Mortality in Elderly People: A Time-Series Study in Sao Paulo, Brazil. The Tenth Health Effects Institute Annual Conference Program Abstracts for Poster Sessions. p. 43-43". 
Recebido em: 25/05/2019

Aceito em: 26/08/2019

Endereço para correspondência:

(c) (7)

Nilo Sampaio

nilo.samp@terra.com.br

Esta obra está licenciada sob uma Licença Creative

Commons Attribution 3.0 